\title{
We Can Do Better: Challenging Providers to Refrain from Toxic Remarks
}

\author{
Shane Geffe ${ }^{1}$ (D) \\ Received: 9 August 2019 / Accepted: 7 February 2020 / Published online: 20 February 2020 \\ (C) Academic Psychiatry 2020
}

"Are you here to see the guy who thought it was a good idea to drive into oncoming traffic?" the nurse said indecorously. The clinical years of medical education have taught me as much about those that don the stethoscope as they have about infection, disease processes, and human suffering. Certain patients' narratives become tales to be shared sanctimoniously - not terribly different than a white-hot rumor incandesced in the fodder of a high school cafeteria. Where and when we as a society can kick a person while they are down, we often do. Unfortunately, health care is no different. I often wonder why some of the most vulnerable individuals quickly become subject to denigration upon admission to the floor. Quips about pain tolerance, substance abuse, or homelessness traverse the airwaves at a rate much greater than that of a formal verbal handoff. I wish I could say that I have not been complicit. I have responded to uncomfortable jokes about a patient with nervous laughter. I have pointed out a quirk or two in patients I have met. In reality, who are we to judge? Despite an education that does a fair job of implicating an underlying pathophysiology for many of those things that we are most critical about, we still double down on our holier-than-thou stances. Ultimately, we can do better.

The details of the following case have been modified to protect patient identity. During my psychiatry rotation, my attending asked me to visit with a gentleman who had been admitted after a wrong-way motor vehicle collision secondary to alcohol use. Before entering the room, I dove into his chart, admittedly more concerned with the physical consequences of his actions. What was his blood alcohol level? Did he have an anion gap metabolic acidosis? Were his liver enzymes elevated? As I entered the room, I mentally lugged in a list of local resources for people that struggled with alcohol use. On the

Shane Geffe

sgeffe@gmail.com

1 Florida State University College of Medicine, Tallahassee, FL, USA basis of our conversation, I did not find this patient to be suicidal. As often happens to an unsuspecting medical student, the information changed when the physician strolled in. The psychiatrist discovered that the patient had every intent to take his own life. His previous attempt 3 weeks ago had not been effective, so he decided to drive his car into an overpass. He wanted to drink enough to build up the courage. In doing so, he unintentionally entered the highway on the wrong side of traffic. Since the passing of his husband 6 months previous, he had been battling depression. He described his life without the one person whom he once did everything with. I would be shocked to discover that a more apt description of anhedonia had ever been articulated. In his eyes, he had lived a long life of happiness and adventure with someone he considered a soulmate. He no longer saw a reason to continue. However, he did agree to a trial of a selective serotonin reuptake inhibitor. We left the room hopeful that his trajectory would soon take a different direction.

When I visited him the next morning, I blurted out a few questions regarding medication side effects and changes in mood. From his answers, it became clear that he could benefit from a longer conversation about depression and the medications used to treat it. I let him know that depression is common. I informed him that the medication may be helpful in the long run but to temper expectations in the interim. I solicited his thoughts on psychotherapy; he was open to it. My modus operandi was to instill some hope into a despondent patient. I asked him to remain optimistic for himself and his future, and he returned my request with a smile. For the first time as a medical student, I felt as if I did something to help someone. As I extended my hand, he gripped mine tightly, perpetuating the pendulum of the shaking gesture for a full 20 seconds. "Let me tell you something. I was a robotics engineer for the New York Metropolitan Transportation Authority." That is when it hit me. He wanted our lasting impression of him to be that of a person who helped guide subway passengers to safety, not as a patient who "thought it was a good idea to drive into oncoming traffic." In the end, these are facets of humanism that we 
owe all of our patients: respect of their individuality and a genuine attempt to comprehend the paths that led them to us. I was initially enamored with his lab values and diagnoses, yet I failed to see the engineer.

In the hospital, patients become disease states-walking, breathing chief complaints. "Check on my myasthenia guy... watch out for the homeless lady's pseudoseizures...time to visit with my sundowner." This practice dehumanizes those needing care and deteriorates the most fundamental health care tenet: the patient-provider relationship. Discussing patients as if they are diagnostic codes rather than an accumulation of experiences violates the doctrine of compassionate medicine, which beseeches us to keep the person (and not the disease) at the forefront. Imagine William Osler asking one of his resident physicians to interview the "crazy dude who thinks the walls are talking to him." But the stresses of Osler's time are not the tribulations of ours. Fighting a losing battle to infectious disease and dysentery is vastly different from watching patients succumb to largely preventable ailments such as cardiovascular disease and opioid intoxication. Patients are more in control of their health now than they have ever been. Sometimes, in an atmosphere of burnout and jobrelated stressors, we search for a plausible target for our frustrations. In the nineteenth century, it was microscopic organisms. Today, it appears to be individuals and their choices.

How did we get here? Surely there is no simple answer. One of the many plausibilities could be emotional exhaustion [1]. In a burnout climate, the medical workforce is being stretched mentally thinner by the day. Medicine has proven to be inept at helping the helper. Ask any health care employee whose needs come first. Wellness initiatives have become a life net-if that net were made of tissue paper. It is entirely plausible that criticism of those in our care would occur whether there was a high prevalence of moral injury or not. It does seem, however, that unhappiness in the caregiver role becomes kerosene on a match. While the colossal requirements of the job can slowly chew through the provider's morale and idealism, the sense of defeat can become accelerated when the provider is faced with the product of society's indolence regarding mental health: the so-called repeat offenders. There are deeper issues than what reside on the surface, and the majority of people in health care understand this. Sadly, however, with burnout, there is a tendency to ignore the deeper issues and direct anger toward what is in plain sight. This has become a natural response to the chronic emotional toll that moral injury levies. A principled argument requires reflection on the core principles. In the twenty-first century, we could all benefit from reminders of the oaths our predecessors found salience in. Let us strive to be less hypocritical and more Hippocratic. We can all find our inner Florence Nightingale if we search deeply enough. Certainly, the health care community can find ways to avoid disparaging patients, even on our worst days.

Acknowledgments The author thanks Vien Dinh, MD.

\section{Compliance with Ethical Standards}

To de-identify patient data, the author replaced factual, potentially protected health information with masked, fictitious information that prevents identification yet does not alter the conclusions that the author reached as a result or the overall message of the submission.

Disclosure The author states that there is no conflict of interest.

\section{Reference}

1. Panagioti M, Geraghty K, Johnson J, et al. Association between physician burnout and patient safety, professionalism, and patient satisfaction: a systematic review and meta-analysis. JAMA Intern Med. 2018. https://doi.org/10.1001/jamainternmed.2018.3713.

Publisher's Note Springer Nature remains neutral with regard to jurisdictional claims in published maps and institutional affiliations. 